\title{
Conformal Band-Notch UWB Monopole Antenna on Finite Cylindrical Substrates
}

\author{
Emad S. Ahmed \\ Department of Electrical Engineering \\ University of Technology \\ Baghdad, Iraq \\ dr_emad_sa@uotechnology.edu.iq
}

\begin{abstract}
A microstrip-fed new UWB monopole antenna with a band-notch characteristic mounted on the finite cylindrical surface is presented. The proposed antenna consists of a rectangular metal radiation patch fed by a $50 \mathrm{ohm}$ microstrip line and a rectangular ground plane. To achieve ultra-wideband, three modifications are introduced. The first one is to blend the upper and lower corners of the radiating plates. The second one is to remove a circular section from the radiating metal. The third one is to blend the upper corners of the ground plane. The antenna is designed on a substrate with dielectric constant $\varepsilon r=3$ and $1.6 \mathrm{~mm}$ height. The proposed antenna is conformed on finite cylindrical substrates of radiuses 4,5 and $6 \mathrm{~cm}$. The cylindrical structures were simulated through CST microwave studio finite element package. The simulation results, obtained via CST package on the return losses, VSWR and radiation pattern of the antenna are presented. For both planar and conformal antennas, results show that the impedance bandwidth of the designed antenna is from 2-18 GHz with a return loss less than $-10 \mathrm{~dB}$ $($ VSWR $<2)$ and a band rejection of 5-6 GHz for wireless LAN (WLAN), that includes the band 5.15-5.825 GHz limited by IEEE 802.11.a and HIPERLAN/2 with return loss greater than $-10 \mathrm{~dB}$. The proposed simple shaped conformal antenna provides a good radiation pattern and gain between 3.84 and $5.96 \mathrm{dBi}$ over the entire frequency band excluding the rejected band.
\end{abstract}

Keywords- Conformal microstrip antennas; ultra-wideband (UWB); band-notched, cylindrical substrate; monopole antenna.

\section{INTRODUCTION}

Monopole antennas, which feature broad bandwidth and small size, have received intensive attention in ultra-wideband UWB applications, due to the merits of wide impedance bandwidth and omnidirectional radiation pattern [1]. According to the Federal Communication Commission (FCC), UWB systems have been collocated to the bandwidth from 3.1 to 10.6 $\mathrm{GHz}$ [2]. However, over the designated UWB frequency band, there are existing wireless local area network (WLAN) operating bands such as the $5.2 \mathrm{GHz}(5.150-5.350 \mathrm{GHz})$ and $5.8 \mathrm{GHz}(5.725-5.825 \mathrm{GHz})$ bands which may cause interference with UWB [3].
To avoid any electromagnetic interference on wireless LAN systems, many UWB antenna structures and techniques have been studied. Also, broadband antennas of various types with stop-band notch have been reported $[4,5]$.

The use of cylindrical substrates for microwave design is generally driven by the physical attributes of the system rather than by choice, since the analysis and fabrication are more complicated than for a comparable planar implementation. However the cylindrical geometry can offer certain desirable antenna characteristics that are not provided by planar elements [6].

Due to their conformability with the hosting structure, microstrip antennas find many applications related to curved structures such as cylindrical structures, high speed aircrafts and spacecrafts [7]. Antennas mounted on small radius cylinders are increasingly more needed for the development of equipment for communication and industrial applications. The range of applications spans from sensors, goes through wireless access nodes and then up to modern miniaturized spacecrafts [8]. In this paper the design was subdivided into two parts. The first part describes the proposed planar monopole UWB antenna with a notch band characteristic. In the second part, the proposed antenna is conformed on a finite cylindrical substrate with three different radii. The cylindrical structure is simulated using the CST microwave studio package. Results obtained on return loss, VSWR and radiation pattern are presented and discussed.

\section{ANTENNA DESIGN AND CONFGURATION}

\section{A. The Proposed Plannar Antenna Design}

The configuration of the proposed planar ultra-wideband monopole antenna with a band-notch feature is shown in Figure 1. The antenna uses a substrate having $1.6 \mathrm{~mm}$ thickness and relative dielectric constant of 3 . The antenna is formed by two rectangles. On the backside of the substrate, the ground plane is printed to cover only the $50 \mathrm{ohm}$ microstrip feed line. The detailed dimensions of the antenna are shown in Table I. Three modifications are introduced in this patch to improve its operating bandwidth. The first one is to blend each of the upper 
and lower corner edges of the rectangles into an arc with radius of $20 \mathrm{~mm}$. The second modification is to cut a cylindrical section of radius $9.5 \mathrm{~mm}$ centered on the line between the rectangles. The third modification is made on a ground plane; it is designed not to have rectangular but tapered upper corners with $10 \mathrm{~mm}$ radius. The arc shaped patch and tapered ground plane make the best broadband impedance matching of antenna possible $[9,10,11]$.

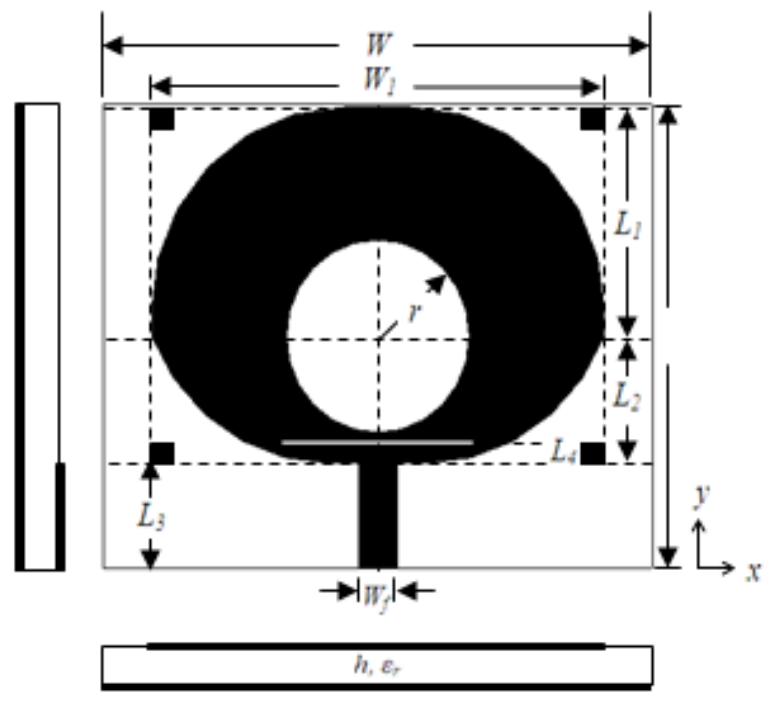

Fig. 1. The geometry of the proposed planar antenna

TABLE I. ANTENNA DIMENSIONS

\begin{tabular}{|c|c|}
\hline Antenna Parameter & Dimension in $\mathbf{~ m m}$ \\
\hline $\boldsymbol{W}$ & 57 \\
\hline $\boldsymbol{W}_{\boldsymbol{1}}$ & 47 \\
\hline $\boldsymbol{W}_{\boldsymbol{f}}$ & 4 \\
\hline $\boldsymbol{L}$ & 45 \\
\hline $\boldsymbol{L}_{\boldsymbol{1}}$ & 22.5 \\
\hline $\boldsymbol{L}_{\boldsymbol{2}}$ & 12.5 \\
\hline $\boldsymbol{L}_{\boldsymbol{3}}$ & 10 \\
\hline $\boldsymbol{L}_{\boldsymbol{4}}$ & 1 \\
\hline $\boldsymbol{r}$ & 9.5 \\
\hline $\boldsymbol{h}$ & 1.6 \\
\hline
\end{tabular}

By inserting a slot of $20 \mathrm{~mm}$ length and $0.2 \mathrm{~mm}$ width on the radiating patch, a notched frequency band from $5-6 \mathrm{GHz}$ is created. The slot length contributes to both the notch center frequency and notch bandwidth, while the slot width contributes mainly on the notch bandwidth. It is easy to design a specific notch-band range by adjusting the slot size $[12,13]$. By selecting the optimal parameters mentioned in Table I, the proposed antenna can be tuned to operate within the UWB band. Figure 2 shows the return loss characteristic of the proposed antenna as well as the effect of the modifications in the range of 2-18 GHz. From Figure 2, it can be clearly indicated that when the rectangular angles of the patch are blended into arcs, the return loss is decreased below $-10 \mathrm{~dB}$ in the range of 4-18 GHz. The third and fourth lines in Figure 2, regarding the second and third modifications, indicate that the bandwidth is further expanded to the range of 2-18 GHz. The fifth line reveals that by cutting a slot in the radiating patch, a stop-band has been created.

\section{B. The Proposed Conformal Antenna Structure}

The conformal antenna configuration is shown in Fig. 3, where a modified planar monopole antenna is conformed on a cylindrical sector substrate of radius $(\mathrm{R}) \mathrm{mm}$. The thickness and dielectric constant of the substrate is $1.6 \mathrm{~mm}$ and 3 respectively. This structure example is of practical interest, since the shape of the most airborne vehicle can be approximately described by a cylindrical sector. In addition, such antennas can be deployed in a special environment, e.g. in the corner of a building.

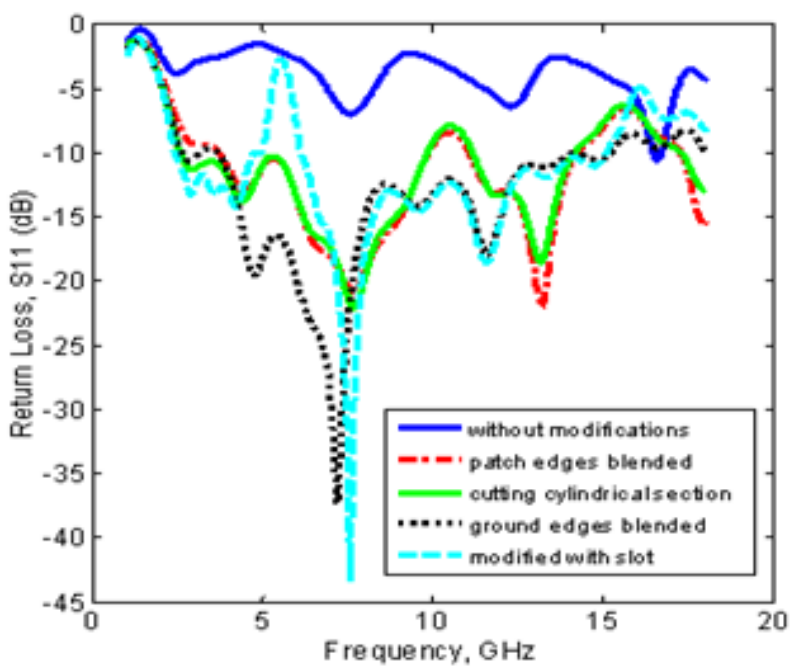

Fig. 2. Return losses for all modifications of the proposed antenna

Front

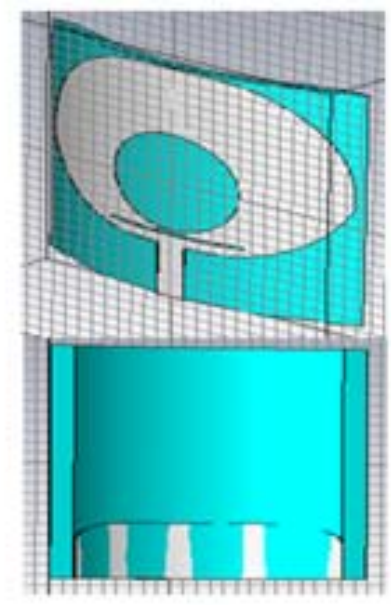

Fig. 3. 3D veiw of the proposed antenna conforming on cylindrical substrate, with front and back views 


\section{Simulation ResUlts AND Discussion}

The cylindrical structures of Figure 3 were simulated through a finite element package, the CST microwave studio ${ }^{\mathrm{TM}}$. Cylinders with radiuses 40, 50, and $60 \mathrm{~mm}$ were analyzed while keeping the rest of the antenna parameters fixed. Figure 4 show the simulated return loss curves for the proposed antenna. As shown in Figure 4, the proposed antenna satisfies the 10dB return loss requirements for the frequency range from $2 \mathrm{GHz}$ to18 GHz. For comparison purposes, the return loss of the planar antenna with slot is also shown in Figure 4. It is found that the impedance bandwidth slightly improves at lower frequencies, up to $5 \mathrm{GHz}$, for all cylinders used in the simulation.

Figure 5 shows the simulated return loss for the proposed antenna structure of the reference planar monopole antenna with slot width dimension of $0.1,0.2$, and $0.3 \mathrm{~mm}$ respectively. It obviously indicates that an UWB bandwidth defined by $10 \mathrm{~dB}$ return loss covering $3.1-10.6 \mathrm{GHz}$ is achieved for all proposed slot width dimension. For all structures, a band rejection of 5-6 GHz with return loss greater than $-10 \mathrm{~dB}$ are obtained.

Figure 6 presents the simulated group delay of the proposed antenna. Group delay variation is generally smooth, except around the notched band and around $8 \mathrm{GHz}$. Figure 6 shows that the proposed antenna has good time/frequency characteristics and a small pulse distortion over the UWB operated band.

Figures 7-8 illustrate the simulated radiation patterns at 3, 4.5, 7.5, 8.5 and $10.5 \mathrm{GHz}$ for a cylindrical structure with $4 \mathrm{~cm}$ and $5 \mathrm{~cm}$ radii. The proposed antenna is characterized by an omnidirectional pattern in the H-plane (xz-plane) while it is a quasi-omnidirectional pattern in the E-plane (yz- plane). It is obvious from these results that the radiation patterns are acceptable over the UWB bandwidth. The gain varies from 3.84 to $5.96 \mathrm{dBi}$ over the operating frequency range while at the notched band, the antenna gain is sharply reduced to a frequency rejected function as shown in Figure 9.

\section{CONCLUSIONS}

This paper proposes and simulates a new simple shape band-notched ultra-wideband antenna. To obtain sufficient matching bandwidth, two modifications are introduced to the radiating patch and one to the ground plane. The modified microstrip fed band-notched monopole antenna is conformed on a cylindrical substrate. The proposed conformal antenna exhibits UWB characteristics and provides a good impedance matching, good radiation patterns and relatively flat gain over the entire frequency band excluding the rejected band. These features of the proposed conformal antenna demonstrate that this antenna is suitable for UWB communication applications, especially for airborne vehicles and at corners of a frames.

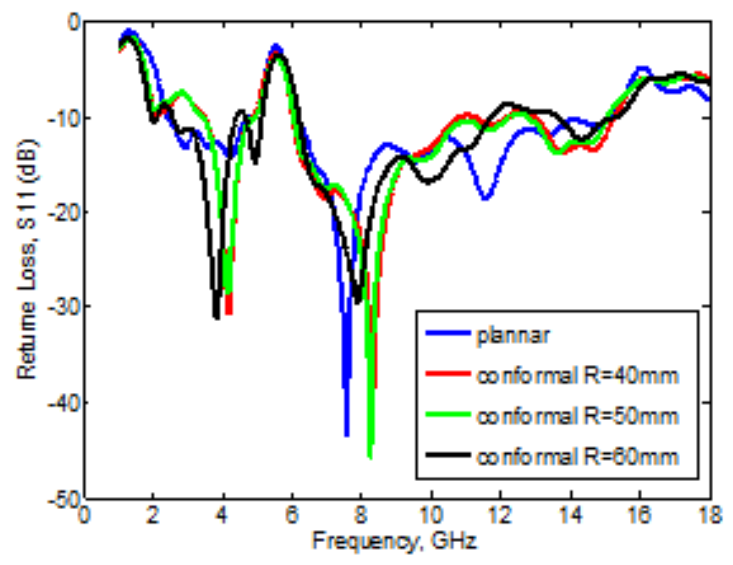

Fig. 4. Return losses of proposed antenaa conformed on cylindrical substrates of radiuses; 40, 50 and $60 \mathrm{~mm}$.

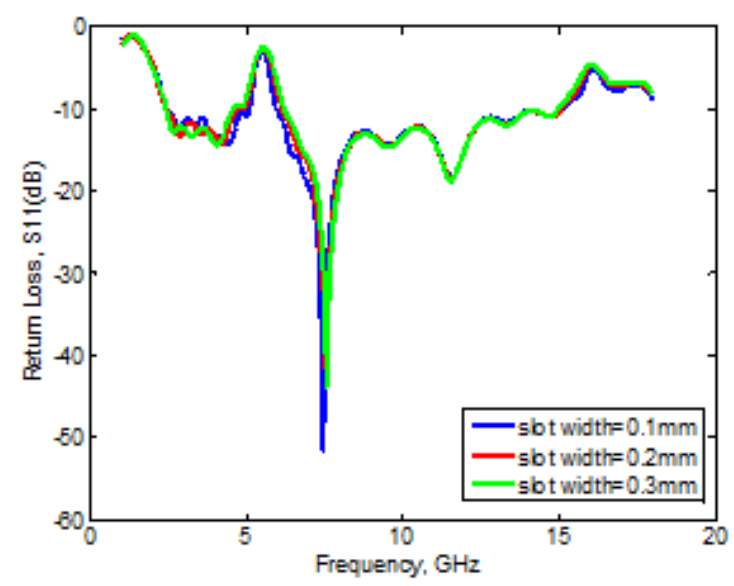

Fig. 5. Return losses of proposed antenna with slot width dimension of $0.1,0.2$, and $0.3 \mathrm{~mm}$ respectively

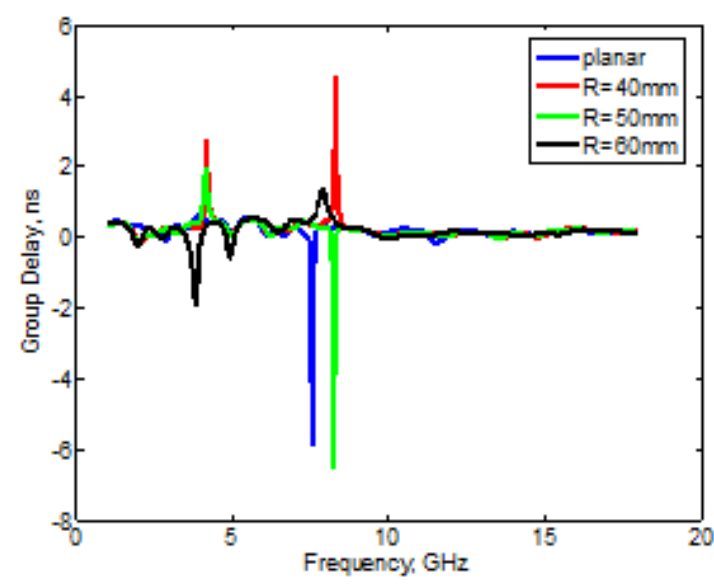

Fig. 6. Group delay of the proposed antenna 

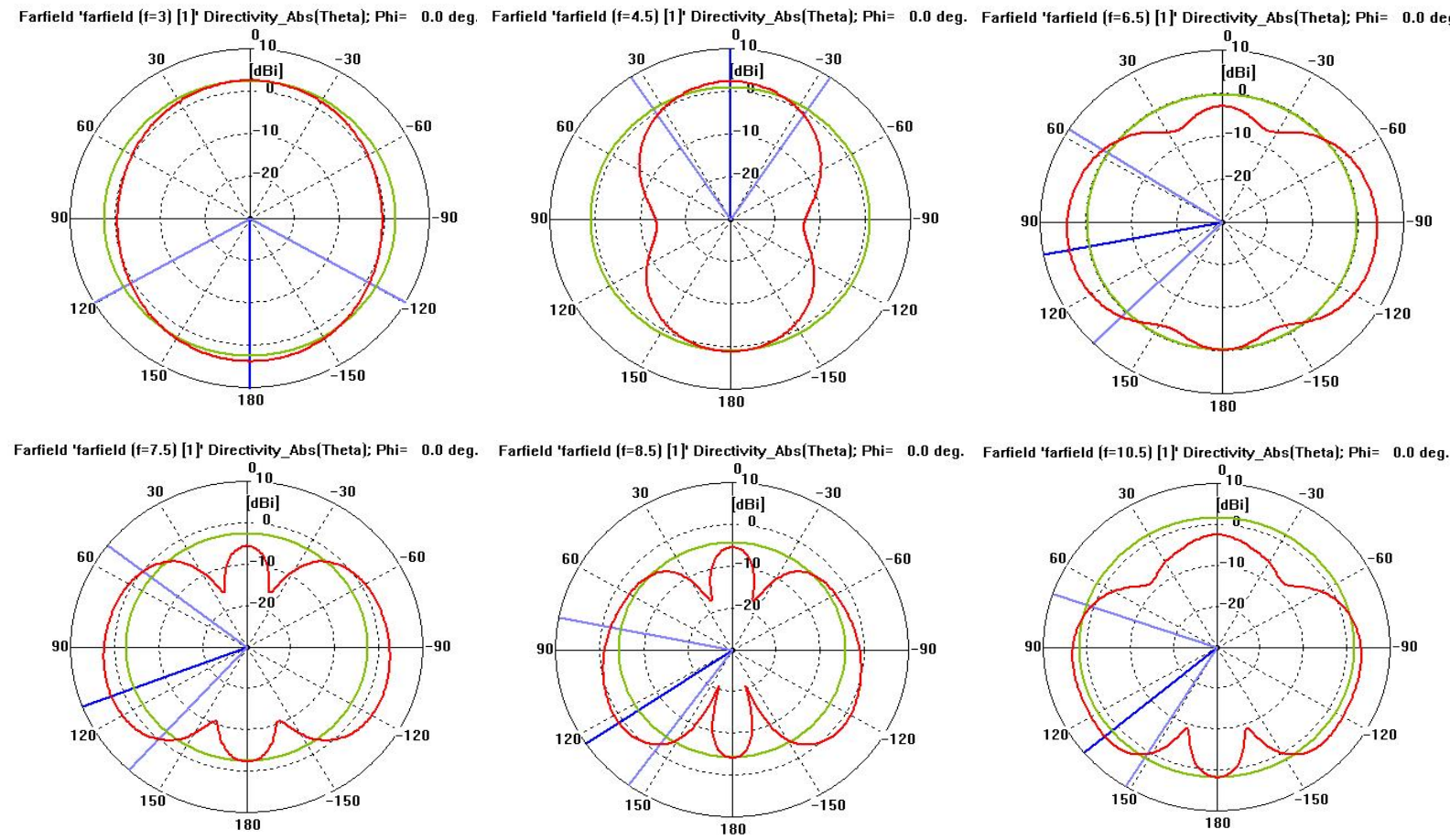

(a) xz- plane field pattern
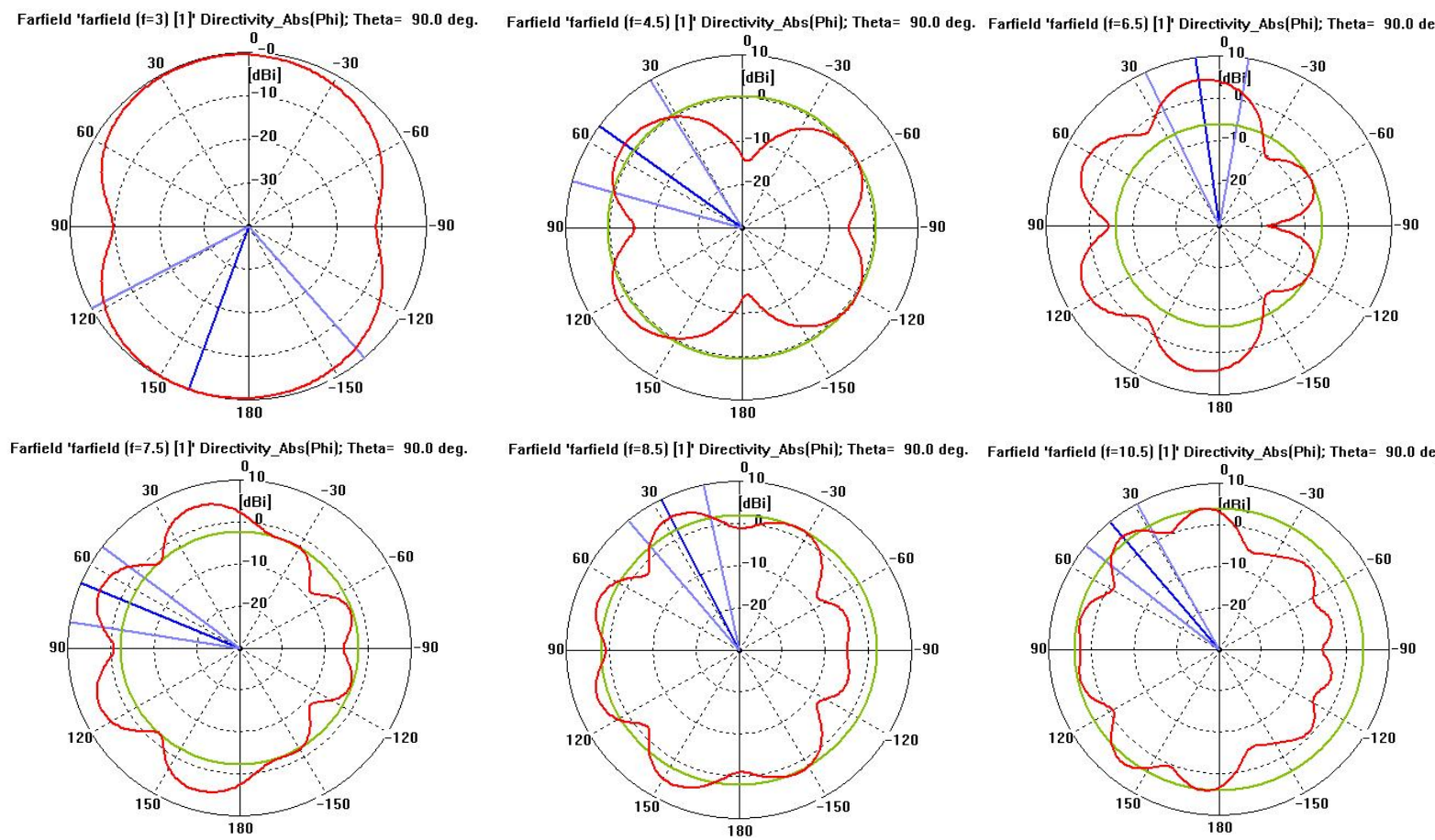

(b) xy- plane field pattern

Fig. 7. Polar plot of far field pattern for cylindrical radius $r=40 \mathrm{~mm}$, (a) xz-plane and (b) xy-plane. 

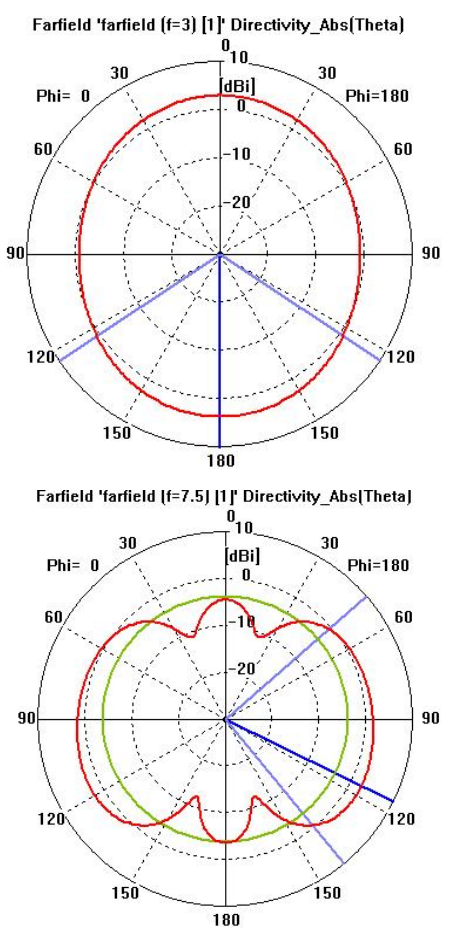

Farfield 'farfield $(f=3)[1]$ ' Directivity_Abs(Phi); Theta $=90.0$ deg.

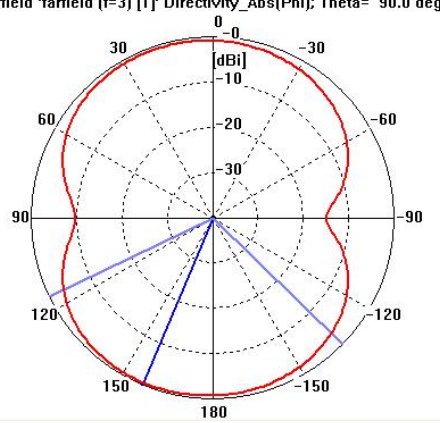

Farfield 'farfield [f=7.5) [1]' Directivity_Abs(Ph)]; Theta= 90.0 de

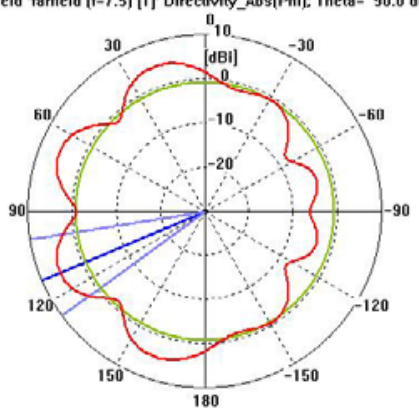

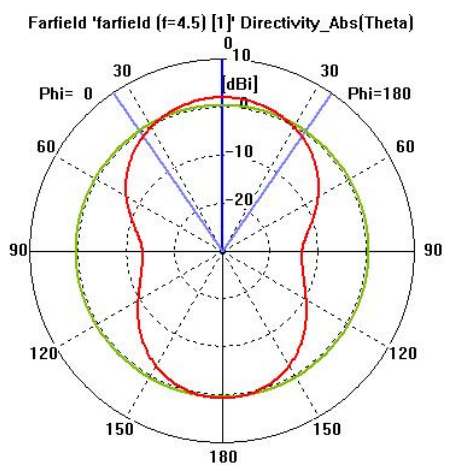

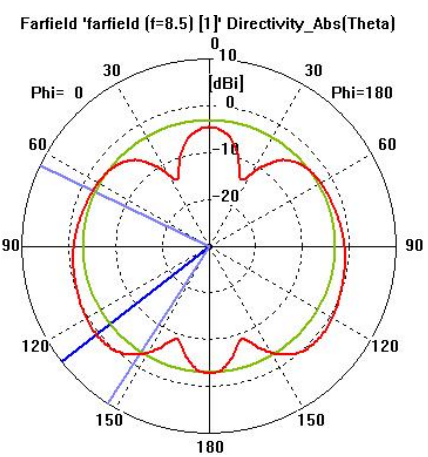

(a) xz-plane far field pattern

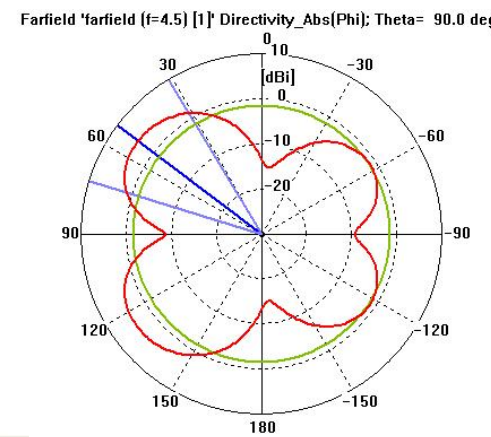

Farfield 'farfield $[\mathrm{f}=\mathbf{8 . 5}$ [ [1]' Directivity_Abs(Phi); Theta= 90.0 deg.
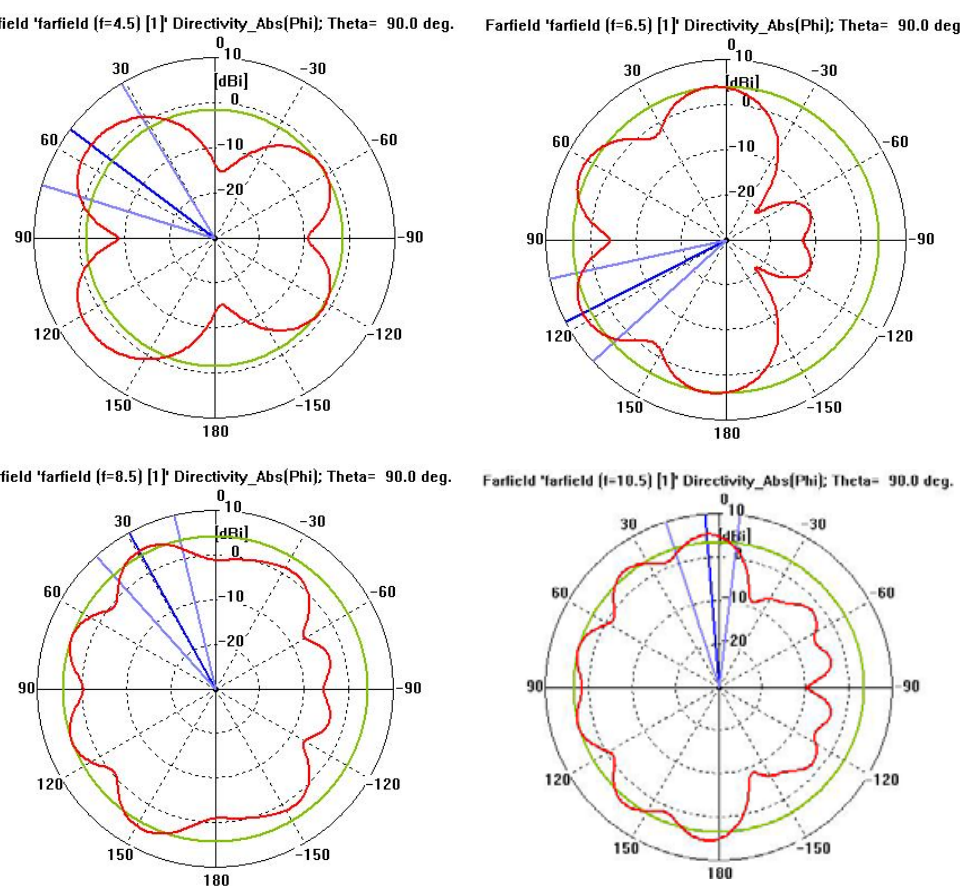

(b) xy-plane far field pattern
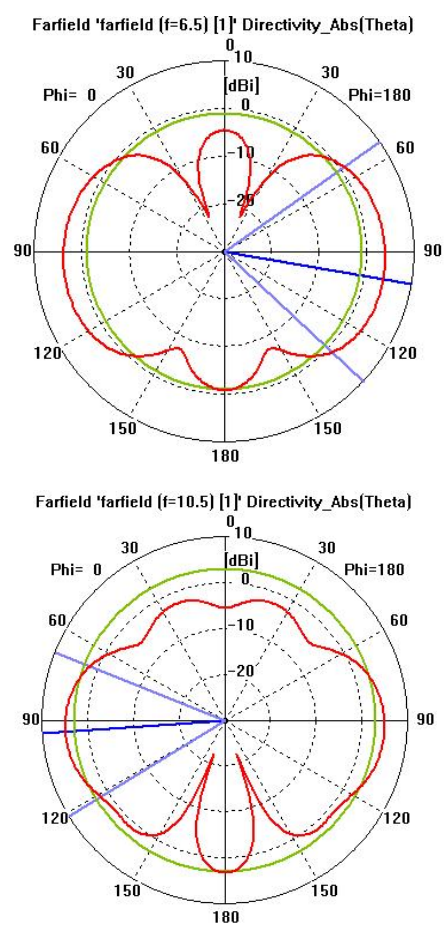

Farfield Parfield (t-10.5) [1] Directivity_Abs(Pli); Theta= $90.0 \mathrm{deg}$.$$
\text { . }
$$ 


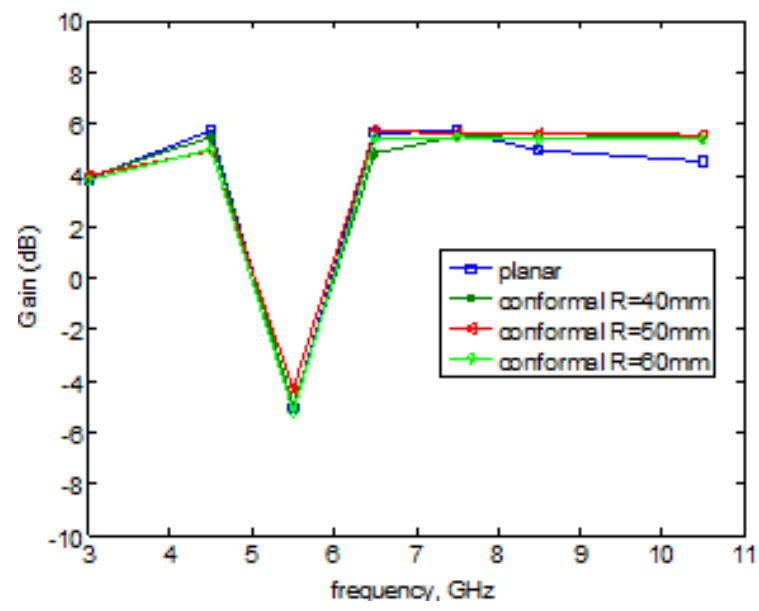

Fig. 9. Gain against UWB frequency band

\section{REFERENCES}

[1] I. Oppermann, M. Hamalainen, J. Iinatti (eds), UWB Theory And Applications, Chichester, U.K., Wiley, 2004

[2] Federal Communications Commission, First Report and Order in the Matter of Revision of Part 15 of the commission's Rules Regarding Ultra-Wideband Transmission Systems, ET Docket 98-153, FCC 02-48, Apr. 22, 2002

[3] K. H. Kim, S. O. Park, "Analysis of the small band-rejected antenna with the parasitic strip for UWB”, IEEE Transactions on Antennas and Propagation, Vol. 54, No. 6, pp. 1688-1692, 2006

[4] S. W. Su, K. L. Wong, C. L. Tang, "Band-notched ultra-wideband planar monopole antenna”, Microwave and Optical Technology Letters, Vol. 44, No. 3, pp. 217-219, 2005

[5] H. K. Yoon, H. R. Kim, K. H. Chang, Y. J. Yoon, , Y. H. Kim, “A study on the UWB antenna with band rejection characteristic”, IEEE Antennas and Propagation Society International Symposium, Vol. 2, pp. 17841787, 2004

[6] M. C. Seardelletti, N. Dib, T. Weller, J. Culver, B. King, “Coplanar waveguide-fed slot antennas on cylindrical substrates”, International Journal of Electronics and Communications, Vol. 59, pp. 25-30, 2005

[7] M. Pirai, H. R. Hassani, "L-probe fed circular polarized wideband planar patch antenna on cylindrical structure”, Progress In Electromagnetics Research C, Vol. 3, pp.161-167, 2008

[8] P. Kabacik, P. Opalka, P. Hornik, "TTC patch antennas made in a conformal form with small radius", EuCAP 2006, First European Conference on Antennas and Propagation, pp. 1-6, Nice, France, 2006

[9] F. Yu, C. Wang, "A CPW-fed novel planar ultra-wideband antenna with a band-notch characteristic”, Radioengineering, Vol. 18, No. 4, pp. 551555, 2009

[10] K. Yin, J. Xu, “Compact ultra-wideband monopole antenna with bandstop characteristic", ICMMT 2008, International Conference on Microwave and Millimeter Wave Technology, Vol. 3, pp. 1174-1176, Nanjing, China, 2008

[11] K. J. Hung, Y. C. Lin, "Open-slot loaded monopole antennas for wlan and uwb applications”, IEEE Antennas and Propagation Society International Symposium, Albuquerque, USA, pp. 4653-4656, 2006

[12] C. Y. Huang, W. C. Hsia, J. S. Kuo, "Planar ultra-wideband antenna with band-notched characteristic", Microwave and Optical Technology Letters, Vol. 48, No. 1, pp. 99-101, 2006

[13] C. Qiu, T. Yuan, Y. Zheng, L. Li, Q. Zhang, "Hybrid shaped bandnotched ultra-wideband patch antenna”, ISAP 2007, International Symposium on Antennas and Propagation, pp. 282-285, Niigata, Japan, 2007

[14] N. Yuan, T. S. Yeo, X. C. Nie, Y. B. Gan, L. W. Li, “Analysis of probefed conformal microstrip antennas on finite grounded substrate”, IEEE Transactions on Antennas and Propagation, Vol. 54, No. 2, pp. 554-563, 2006

\section{AUTHORS PROFILE}

Emad S. Ahmed was born in Mosul, Iraq, in 1960. He received the B.Sc. degree in Electrical Engineering from Mosul University, Mosul, Iraq, in 1982, the M.Sc. degree and Ph.D. degree from Al-Rasheed College for Engineering and Science, Baghdad, Iraq, in 1990 and 2002 respectively. He is currently an associate professor for the Communication Engineering,University of Technology, Baghdad, Iraq. His research interests include wireless communication, microwave circuits design, antennas and wave propagation. Dr. Emad is an IEEE and AP-Society member. 